\title{
Hearing preservation after Gamma Knife radiosurgery for cerebellopontine angle meningiomas
}

\author{
Amr M. N. El-Shehaby, MD, PhD, 1,2 Wael A. Reda, MD, PhD, 1,2 Khaled M. Abdel Karim, MD, PhD,, \\ Ahmed M. Nabeel, MD, PhD, ${ }^{1,5}$ Reem M. Emad Eldin, MD, PhD, ${ }^{1,4}$ and \\ Sameh R. Tawadros, MD, PhD ${ }^{1,2}$
}

${ }^{1}$ Gamma Knife Center Cairo; ${ }^{2}$ Neurosurgery Department, and ${ }^{3}$ Clinical Oncology Department, Faculty of Medicine, Ain Shams University, Cairo; ${ }^{4}$ Radiation Oncology Department, National Cancer Institute, Cairo University, Cairo; and ${ }^{5}$ Neurosurgery Department, Faculty of Medicine, Benha University, Qalubya, Egypt

\begin{abstract}
OBJECTIVE The objective of this study was to assess hearing function after Gamma Knife treatment of cerebellopontine angle (CPA) meningiomas and assess factors affecting hearing outcome. Additionally, the authors opted to compare these results with those after Gamma Knife treatment of vestibular schwannomas (VSs), because most of the information on hearing outcome after stereotactic radiosurgery (SRS) comes from reports on VS treatment. Hearing preservation, to the best of the authors' knowledge, has never been separately addressed in studies involving Gamma Knife radiosurgery (GKRS) for CPA meningiomas.

METHODS This study included all patients who underwent a single session of GKRS between 2002 and 2014. The patients were divided into two groups. Group A included 66 patients with CPA meningiomas with serviceable hearing and tumor extension into the region centered on the internal auditory meatus. Group B included 144 patients with VSs with serviceable hearing. All patients had serviceable hearing before treatment (Gardner-Robertson [GR] Grades I and II). The median prescription dose was $12 \mathrm{~Gy}$ (range 10-12 Gy) in both groups. The median follow-up of groups $A$ and $B$ was 42 months (range 6-149 months) and 49 months (range 6-149 months), respectively.
\end{abstract}

RESULTS At the last follow-up, the tumor control rate was $97 \%$ and $94 \%$ in groups A and B, respectively. Hearing preservation was defined as maintained serviceable hearing according to GR hearing score. The hearing preservation rate was $98 \%$ and $66 \%$ and the 7 -year actuarial serviceable hearing preservation rate was $75 \%$ and $56 \%$, respectively, between both groups. In group A, the median maximum cochlear dose in the patients with stable and worsened hearing grade was 6.3 Gy and $5.5 \mathrm{~Gy}$, respectively. In group B, factors affecting hearing preservation were cochlear dose $\leq 7 \mathrm{~Gy}$, follow-up duration, and tumor control. The only determinant of hearing preservation between both groups was tumor type. CONCLUSIONS GKRS for CPA meningiomas provides excellent hearing preservation in addition to high tumor control rate. Hearing outcome is better with CPA meningiomas than with VSs. Further long-term prospective studies on determinants of hearing outcome after GKRS for CPA meningiomas should be conducted.

https://thejns.org/doi/abs/10.3171/2018.7.GKS181308

KEYWORDS Gamma Knife; cerebellopontine; meningiomas; vestibular schwannomas; hearing; stereotactic radiosurgery

$\mathrm{O}$ NE of every 10 intracranial tumors arises in the cerebellopontine angle (CPA), most of which are vestibular schwannomas (VSs), comprising $80 \%-85 \%$, and less commonly meningiomas, accounting for $10 \%-15 \%,{ }^{1,5,45}$ Because of the close proximity of CPA meningiomas to critical neurovascular structures, resection is surgically challenging. Stereotactic radiosurgery (SRS) as an adjuvant or alternative treatment for skull base meningiomas has demonstrated high efficacy and safety. ${ }^{32,36,40,42,47}$ However, the presence of the hearing apparatus in the vicinity of CPA meningiomas theoretically makes hearing function at risk during Gamma Knife radiosurgery (GKRS). Hearing preservation after GKRS and possible outcome predictors has been extensively investigated and reported in relation to VSs. Yet it is unknown whether these results relating to hearing outcome or predictive factors of outcome apply to CPA meningiomas treated by SRS.

ABBREVIATIONS ARE = adverse radiation event; CPA = cerebellopontine angle; FSRT = fractionated stereotactic radiotherapy; GKRS = Gamma Knife radiosurgery; GR = Gardner-Robertson; IAC = internal auditory canal; IC = intracanalicular; SRS = stereotactic radiosurgery; VS = vestibular schwannoma.

SUBMITTED May 18, 2018. ACCEPTED July 5, 2018.

INCLUDE WHEN CITING DOI: 10.3171/2018.7.GKS181308. 
The primary objective of this study was to assess hearing function after GKRS for CPA meningiomas and assess factors affecting hearing outcome. A secondary objective was to compare those results to our results using GKRS for VSs.

\section{Methods \\ Patient Population}

In this retrospective study, we included patients who underwent a single session of GKRS between 2002 and 2014. The patients were divided into two groups. Group A included 66 patients with CPA meningiomas with serviceable hearing and tumor extension into the region centered on the internal auditory meatus, with or without extension into the internal auditory canal (IAC). Group B included 144 patients with VSs with serviceable hearing. Patients included in this study were only those with serviceable hearing before treatment (Gardner-Robertson [GR] Grades I and II). We excluded patients with meningiomatosis, neurofibromatosis type 2 , tumors invading the petrous bone, and histopathologically nonbenign meningiomas (Fig. 1).

For nonoperated meningioma cases, the radiological criteria for diagnosis were homogenous contrast enhancement, extraaxial location, and dural tail. As for nonoperated VS cases, the radiological criteria for diagnosis were heterogeneous contrast enhancement, widening of the porus, hyperintensity to adjacent brain on T2-weighted images, and for small tumors, direct location on the vestibulocochlear nerve. Hearing assessment was based on pure tone average and speech discrimination.

\section{Radiosurgical Technique}

The Leksell stereotactic head frame was attached to the patient's head using local anesthesia (model G, Elekta AB). Imaging was based on contrast-enhanced T1-weighted sequences plus T2-weighted MR sequences with $1.6-\mathrm{mm}$ slice thickness using high-resolution 1.5-T MRI (Genesis Sigma, General Electric). Stereotactic images were imported into the GammaPlan workstation (Elekta $\mathrm{AB}$ ). The treatment was performed using the Gamma Knife Model $\mathrm{C}$ (Elekta Instruments, Inc.). The target volume was drawn in all the MRI slices.

\section{Statistical Analysis}

The mean and median values were presented for normal and nonnormal distributions, respectively. Ranges for continuous variables were determined and percentages for categorical variables were reported. Normality was assessed using the Shapiro-Wilk test. Statistical analysis for categorical variables was assessed using the chi-square and Fisher exact tests. Statistics of means were conducted using the 2-sample independent sample t-test, with and without equal variance, as determined by Levene's test. The Wilcoxon rank-sum test was used when variables had nonnormal distribution. Univariate and multivariate analyses were performed for hearing outcome (stable vs worse), hearing function (serviceable vs nonserviceable), and tumor control (control vs progression). Kaplan-Meier risk analysis was performed for hearing outcome, hearing function, and tumor control, as well as for determining 5- and 7-year hear-

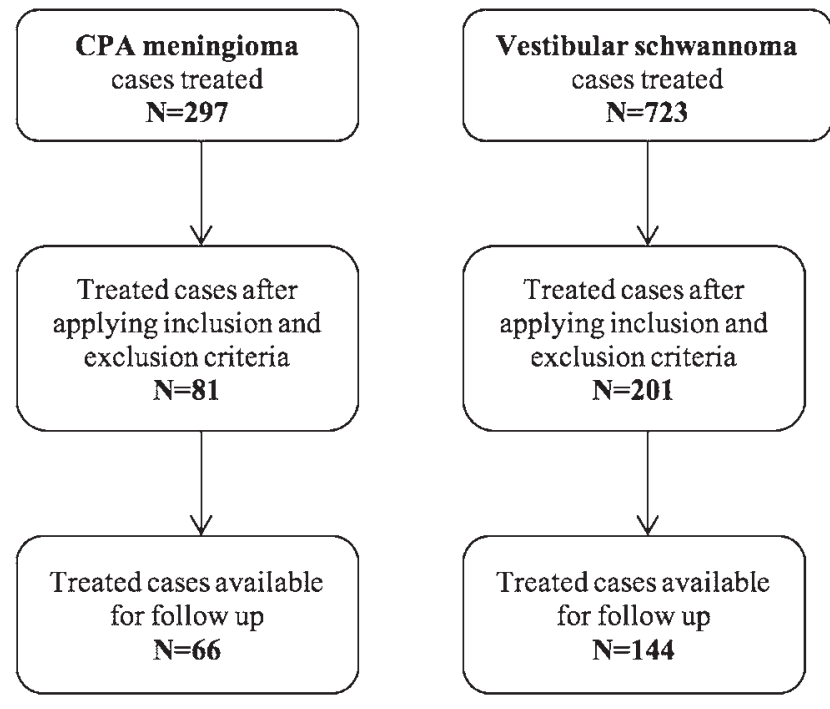

FIG. 1. Flow diagram showing the selection process for patients with CPA meningiomas and VSs included in the study for analysis.

ing preservation rate and progression-free survival. Multivariate analysis was performed using multivariate logistic regression analysis by entering independent variables that were found to be significant $(\mathrm{p}<0.05)$ in univariate analysis. Those $\mathrm{p}$ values $<0.05$ were considered statistically significant and the $95 \%$ confidence interval was reported for each statistically significant variable.

Covariates tested for significance were age, sex, previous surgery, tumor extension inside the IAC, tumor type, length of tumor inside the IAC, maximum tumor diameter in CPA (measured from the most lateral end of the tumor in the IAC to the most medial end of the tumor in the same plane), pretreatment hearing grade, tumor volume, prescription dose, maximum and mean target dose, maximum and mean dose to cochlea, follow-up duration, tumor diameter $\leq 3 \mathrm{~cm}$ or $>3 \mathrm{~cm}$, maximum cochlear dose $\leq 5$ Gy or $>5$ Gy, maximum cochlear dose $\leq 6$ Gy or $>6$ Gy, maximum cochlear dose $\leq 7$ Gy or $>7 \mathrm{~Gy}$, and mean cochlear dose $\leq 4$ Gy or $>4$ Gy.

Statistical analyses were conducted for the whole cohort, then for groups A and B separately. The inferential statistical results for group A regarding hearing function were excluded because there was only 1 case of loss of serviceable hearing in this group after treatment. Also, a separate analysis was performed for the group of patients with GR Grade I hearing before treatment for the whole cohort, then for groups A and B separately. The radiological and clinical data reported in the study were those obtained from the latest follow-up.

\section{Follow-Up}

Imaging follow-up examinations using contrast-enhanced MRI were conducted at 3-month intervals for the first year and then at 6-month intervals for the second year, and annually thereafter. Additional imaging was obtained when a patient developed new symptoms or experienced worsening of any preexisting symptoms. Every patient's history and examination findings were recorded and com- 
pared with those documented prior to treatment. Radiological follow-up was undertaken by performing contrastenhanced MRI, including T2-weighted series. A $20 \%$ or more change in the tumor diameter measurements in at least two of the largest axes was considered significant. In addition to imaging, an audiometry test with speech discrimination score was performed before treatment and at every follow-up evaluation.

Hearing function after GKRS was determined according to the serviceability (i.e., serviceable/nonserviceable) as defined earlier. Hearing outcome was determined as either stable if no change in grade, or worse if there was decrease of the hearing by one grade or more (considered hearing deterioration). Written informed consent was obtained from all patients or their guardians.

\section{Results}

\section{Patient Demographics and Tumor Attributes}

The mean age of patients in group A was 50 years, as compared to 44 years in group B (Table 1). The majority of patients in both groups were radiologically diagnosed (group A, $\mathrm{n}=60$ [91\%], and group B, $\mathrm{n}=141$ [98\%]). Only 6 patients $(9 \%)$ and 5 patients $(3.5 \%)$ in groups $\mathrm{A}$ and $\mathrm{B}$, respectively, had undergone prior surgery. Females were the predominant sex in group A and there was an almost equal sex distribution in group B. Regarding hearing grade before treatment, most of the group A patients were GR Grade I (86\%) as opposed to group B patients with $56 \%$ GR Grade I. The main presentations in group A patients were facial pain and numbness, vertigo, and disequilibrium. In group B patients, the main presentations were tinnitus, hearing loss, and vertigo (Table 1). Intracanalicular (IC) tumor extension was observed in two-thirds of the patients in group A, but in all the patients in group B. The mean tumor volume was significantly greater among group A patients $\left(10 \mathrm{~cm}^{3}\right.$, range $\left.1.5-41.4 \mathrm{~cm}^{3}\right)$ than among group B patients $\left(3.6 \mathrm{~cm}^{3}\right.$, range $0.02-18.6 \mathrm{~cm}^{3}$; Table 2). The mean tumor diameter in the CPA was approximately equal in both groups. The length of IC tumor extension was greater among group B patients than group A patients (7.7 $\mathrm{mm}$ and $4.1 \mathrm{~mm}$, respectively).

The mean prescription dose was 11.7 Gy and 11.9 Gy in groups $\mathrm{A}$ and $\mathrm{B}$, respectively. The mean maximum cochlear dose was higher in group B patients than in group A patients (7.7 Gy vs 6.2 Gy). The mean follow-up duration for groups A and B was 42 months (range 6-149 months) and 49 months (range 6-149 months), respectively (Table $3)$. For the entire cohort, in patients with pretreatment GR hearing Grades I and II, the mean length of IC tumor extension was $5.9 \mathrm{~mm}$ and $7.9 \mathrm{~mm}$, respectively. Also, the mean distance between lateral tumor margin and cochlea was $4.7 \mathrm{~mm}$ and $2.8 \mathrm{~mm}$, respectively. For group A, in patients with GR Grade I and Grade II hearing, the mean length of IC tumor extension was $4 \mathrm{~mm}$ and $5.3 \mathrm{~mm}$, respectively. Also, the mean distance between lateral tumor margin and cochlea was $6.7 \mathrm{~mm}$ and $5.3 \mathrm{~mm}$, respectively. For group B, in patients with GR Grade I and Grade II hearing, the mean length of IC tumor extension was 7.2 $\mathrm{mm}$ and $8.3 \mathrm{~mm}$, respectively. The mean distance between lateral tumor margin and cochlea was $3.2 \mathrm{~mm}$ and 2.5
TABLE 1. Patient demographics

\begin{tabular}{|c|c|c|c|}
\hline Variable & $\begin{array}{c}\text { CPA Meningioma } \\
\text { (Group A) }\end{array}$ & $\begin{array}{c}\text { VS } \\
\text { (Group B) }\end{array}$ & $\begin{array}{c}p \\
\text { Value }\end{array}$ \\
\hline No. of patients & 66 & 144 & - \\
\hline Mean age (range), yrs & $50(30-75)$ & $44(16-71)$ & $<0.0001$ \\
\hline Previous surgery, $\mathrm{n}(\%)$ & $6(9)$ & $5(4)$ & 0.1 \\
\hline Sex, n (\%) & & & $<0.0001$ \\
\hline Male & $17(26)$ & $82(57)$ & \\
\hline Female & $49(74)$ & $62(43)$ & \\
\hline $\begin{array}{l}\text { Hearing grade before } \\
\text { GKRS, } n(\%)\end{array}$ & & & $<0.0001$ \\
\hline Grade I & $57(86)$ & $80(56)$ & \\
\hline Grade II & $9(14)$ & $64(44)$ & \\
\hline IC extension, $\mathrm{n}(\%)$ & $44(67)$ & $144(100)$ & NA \\
\hline \multicolumn{4}{|l|}{ Presenting symptom, $\mathrm{n}$} \\
\hline Facial pain & 18 & 8 & \\
\hline Facial numbness & 16 & 12 & \\
\hline Facial spasm & - & 1 & \\
\hline Facial weakness & - & 3 & \\
\hline Vertigo & 16 & 32 & \\
\hline Disequilibrium & 18 & 14 & \\
\hline Tinnitus & 13 & 101 & \\
\hline Diplopia & 4 & - & \\
\hline Hearing loss & 4 & 75 & \\
\hline Bulbar symptoms & 1 & 1 & \\
\hline Headache & 13 & 21 & \\
\hline Hydrocephalus & 9 & 4 & \\
\hline
\end{tabular}

$N A=$ not applicable ( $p$ value could not be calculated because all patients in the VS group had IC extension).

Boldface type indicates statistical significance.

$\mathrm{mm}$, respectively. There was a significant correlation between the length of IC tumor extension and hearing grade before treatment $(\mathrm{p}<0.0001)$ for the whole cohort. The same correlation applied to the distance between lateral tumor margin and cochlea $(\mathrm{p}<0.0001)$. The same correlation was found for group B patients only $(\mathrm{p}=0.02)$.

\section{Radiological Outcome}

In group A patients the tumor shrank in 26 (39.4\%), remained stable in $38(57.6 \%)$, and progressed in $2(3 \%)$. The overall tumor control rate was $97 \%$ (Table 3). In group B patients the tumor shrank in $63(43.8 \%)$, remained stable in $72(50 \%)$, and progressed in $9(6.3 \%)$. The overall tumor control rate was $94 \%$. There were no significant predictive factors for tumor control in either group. Shorter followup duration was a predictive factor in tumor shrinkage in group B $(p<0.0001)$. Symptomatic edema was observed in 2 patients in group A. In one of them it was an adverse radiation event (ARE) and in the other it was associated with tumor progression. AREs occurred in 6 patients in group B and all were temporary.

\section{Audiological Outcome}

In group A after treatment, 51 patients (77\%) were GR 
TABLE 2. Treatment parameters and tumor attributes

\begin{tabular}{|c|c|c|c|}
\hline Variable & $\begin{array}{c}\text { CPA Meningioma } \\
(\text { Group A })\end{array}$ & $\begin{array}{c}\text { VS } \\
\text { (Group B) }\end{array}$ & $\begin{array}{c}p \\
\text { Value }\end{array}$ \\
\hline Tumor volume $\left(\mathrm{cm}^{3}\right)$ & & & $<0.0001$ \\
\hline Mean \pm SD & $10 \pm 8.7$ & $3.6 \pm 4.5$ & \\
\hline Range & $1.5-41.4$ & $0.02-18.6$ & \\
\hline Median & 7.1 & 1.7 & \\
\hline Dose (Gy) & & & 0.001 \\
\hline Mean \pm SD & $11.7 \pm 0.6$ & $11.9 \pm 0.3$ & \\
\hline Range & $10-12$ & $10-12$ & \\
\hline Median & 12 & 12 & \\
\hline Isodose (\%) & & & 0.003 \\
\hline Mean \pm SD & $49.9 \pm 2.1$ & $51 \pm 3.9$ & \\
\hline Range & $40-60$ & $45-70$ & \\
\hline Median & 50 & 50 & \\
\hline Coverage (\%) & & & 0.3 \\
\hline Mean \pm SD & $95.2 \pm 2.2$ & $95.6 \pm 2.5$ & \\
\hline Range & $91-99$ & $90-100$ & \\
\hline Median & 95 & 96 & \\
\hline Max dose (Gy) & & & 0.91 \\
\hline Mean \pm SD & $23.6 \pm 1.6$ & $23.6 \pm 1.6$ & \\
\hline Range & $20-30.2$ & $17.2-26.7$ & \\
\hline Median & 24 & 24.1 & \\
\hline CPA tumor diameter (mm) & & & 0.95 \\
\hline Mean \pm SD & $19.3 \pm 5.6$ & $19.4 \pm 7.9$ & \\
\hline Range & $6-35$ & $4-42$ & \\
\hline Median & 19 & 18 & \\
\hline Length of IC tumor (mm) & & & $<0.0001$ \\
\hline Mean \pm SD & $4.1 \pm 3.7$ & $7.7 \pm 2.7$ & \\
\hline Range & $0-13$ & $2-14$ & \\
\hline Median & 4 & 8 & \\
\hline $\begin{array}{l}\text { Distance from lat tumor to } \\
\text { cochlea }(\mathrm{mm})\end{array}$ & & & $<0.0001$ \\
\hline Mean \pm SD & $6.5 \pm 3$ & $3 \pm 2$ & \\
\hline Range & $0-13$ & $2-14$ & \\
\hline Median & 7.5 & 2 & \\
\hline Max cochlear dose (Gy) & & & $<0.0001$ \\
\hline Mean \pm SD & $6.2 \pm 2$ & $7.7 \pm 2.2$ & \\
\hline Range & $1.5-11.1$ & $2.8-13.9$ & \\
\hline Median & 6 & 7.5 & \\
\hline Mean cochlear dose (Gy) & & & 0.89 \\
\hline Mean \pm SD & $4.9 \pm 1.7$ & $4.9 \pm 1.4$ & \\
\hline Range & $0.9-9.6$ & $1.9-10$ & \\
\hline Median & 4.6 & 4.9 & \\
\hline
\end{tabular}

Boldface type indicates statistical significance.

Grade I and 14 (21\%) were GR Grade II (Table 3). In 1 patient $(2 \%)$ hearing became nonserviceable after treatment, deteriorating to GR Grade III. The hearing preservation rate was $98 \%$. Regarding hearing outcome, the hearing grade remained unchanged in 59 patients $(89 \%)$ but there was deterioration in the hearing grade in 7 patients $(11 \%)$. The 5- and 7-year actuarial preservation rates were $82 \%$
TABLE 3. Treatment outcome

\begin{tabular}{lcc}
\hline \multicolumn{1}{c}{ Outcome Variable } & $\begin{array}{c}\text { CPA Meningioma } \\
\text { (Group A) }\end{array}$ & $\begin{array}{c}\text { VS } \\
\text { (Group B) }\end{array}$ \\
\hline Hearing preservation rate & $98 \%$ & $66 \%$ \\
\hline $\begin{array}{l}\text { 5- \& 7-yr actuarial hearing preser- } \\
\text { vation rates }\end{array}$ & $82 \%, 75 \%$ & $72 \%, 56 \%$ \\
\hline Hearing grade after GKRS, n (\%) & & \\
\hline Grade I & $51(77 \%)$ & $34(24 \%)$ \\
\hline$\quad$ Grade II & $14(21 \%)$ & $61(42 \%)$ \\
\hline $\begin{array}{l}\text { Mean time to hearing deterioration } \\
\text { (range), mos }\end{array}$ & $15(6-22)$ & $18(5-69)$ \\
\hline Tumor control rate & $97 \%$ & $94 \%$ \\
\hline Mean follow-up duration, mos & 42 & 49 \\
\hline
\end{tabular}

and $75 \%$, respectively. The mean time to hearing deterioration was 15 months (range 6-22 months). The patients with GR Grade I hearing before treatment in group A had unchanged hearing in 51/57 (89.5\%). All patients had preserved hearing after treatment with a hearing preservation rate of $100 \%$. For the patients with GR Grade II hearing before treatment in group A, the hearing was unchanged in $8 / 9(89 \%)$ and hearing was preserved in $8 / 9(89 \%)$. The actuarial preservation rate could not be calculated because all patients in this subgroup had preserved hearing.

In group B after treatment, 34 patients $(24 \%)$ were GR Grade I, 61 (42\%) were GR Grade II, 39 (27\%) were GR Grade III, and $10(7 \%)$ were GR Grade V. Hearing in 49 patients $(34 \%)$ became nonserviceable after treatment. The hearing preservation rate was $66 \%$ (Table 3 ). Regarding hearing outcome, the hearing grade remained unchanged in 69 patients (48\%) but there was deterioration in the hearing grade in 75 patients $(52 \%)$. The 5 - and 7 -year actuarial preservation rates were $72 \%$ and $56 \%$, respectively. The mean time to hearing deterioration was 18 months (range 5-69 months; Table 3). The patients with GR Grade I hearing before treatment in group B had unchanged hearing in 34/80 (42.5\%). Preserved hearing was found in 60/80 (75\%). For the patients with GR Grade II hearing before treatment in group B, hearing was unchanged in 35/64 (55\%) and hearing was preserved in $35 / 64(55 \%)$. The 5- and 7-year actuarial preservation rates were $77 \%$ and $62 \%$, respectively.

Hearing outcome in GR Grade II patients for the whole cohort was unchanged in 85/137 (62\%) while hearing was preserved in 117/137 (85\%). For GR Grade II patients, unchanged hearing was observed in 43/73 (59\%) and hearing preservation occurred in 43/73 (59\%).

The determinants of better hearing outcome for the whole cohort were tumor type (CPA meningioma; $\mathrm{p}<$ $0.0001)$ and shorter follow-up duration $(p=0.04)$ in multivariate analysis (Table 4). The determinants of preservation of hearing function were CPA meningioma $(\mathrm{p}=$ $0.007)$, shorter follow-up duration $(\mathrm{p}=0.002)$, and tumor control $(\mathrm{p}=0.006)$ for the whole cohort in multivariate analysis (Table 5).

The determinant of better hearing outcome according to tumor type was shorter follow-up duration $(\mathrm{p}=0.03)$ in a multivariate analysis for group B only (Table 6). Regard- 
TABLE 4. Significant covariates in better hearing outcome (stable/worse) tested for the entire cohort

\begin{tabular}{|c|c|c|c|c|}
\hline \multirow[b]{2}{*}{ Covariate } & \multirow{2}{*}{$\begin{array}{c}\text { Univariate } \\
\text { Analysis } \\
\text { ( } p \text { value) }\end{array}$} & \multicolumn{3}{|c|}{ Multivariate Analysis } \\
\hline & & OR & $95 \% \mathrm{Cl}$ & $\mathrm{p}$ Value \\
\hline $\begin{array}{l}\text { Tumor type (CPA menin- } \\
\text { gioma) }\end{array}$ & $<0.0001$ & 6.38 & $2.53-18.09$ & $<0.0001$ \\
\hline $\begin{array}{l}\text { Length of IC tumor } \\
\text { (shorter) }\end{array}$ & $<0.0001$ & NS & NS & NS \\
\hline $\begin{array}{l}\text { Distance from lat tumor to } \\
\text { cochlea }(\mathrm{mm})\end{array}$ & $<0.0001$ & NS & NS & NS \\
\hline Max cochlear dose (lower) & 0.03 & NS & NS & NS \\
\hline $\begin{array}{l}\text { Follow-up duration } \\
\text { (shorter) }\end{array}$ & 0.001 & 0.99 & $0.98-100$ & 0.04 \\
\hline Max cochlear dose (Gy) & & NS & NS & NS \\
\hline$\leq 7$ & 0.02 & & & \\
\hline \multicolumn{5}{|l|}{$>7$} \\
\hline Max tumor diameter $(\mathrm{cm})$ & & NS & NS & NS \\
\hline$\leq 3$ & 0.003 & & & \\
\hline \multicolumn{5}{|l|}{$>3$} \\
\hline Tumor control & 0.02 & NS & NS & NS \\
\hline
\end{tabular}

$\mathrm{Cl}=$ confidence interval; $\mathrm{NS}=$ nonsignificant; $\mathrm{OR}=$ odds ratio.

Boldface type indicates statistical significance.

ing hearing functionality, calculations were only made for group B because only 1 patient lost functionality after treatment in group A. The determinants of preserved hearing function after separation by tumor type were shorter follow-up duration $(\mathrm{p}=0.003)$, maximum cochlear dose of $\leq 7 \mathrm{~Gy}(\mathrm{p}=0.04)$, and tumor control $(\mathrm{p}=0.007)$ in a multivariate analysis (Table 7).

In group A, the maximum cochlear dose among patients with unchanged and worse hearing was $6.3 \mathrm{~Gy}$ and $5.5 \mathrm{~Gy}$, respectively, which was statistically insignificant $(p=0.29)$. In group $\mathrm{B}$, the maximum cochlear dose among patients with unchanged and worse hearing was $7.6 \mathrm{~Gy}$ and $7.8 \mathrm{~Gy}$, respectively, which was statistically insignificant $(\mathrm{p}=0.67)$.

\section{Discussion}

\section{Tumor Control After Radiosurgery}

SRS for skull base meningiomas has been extensively reported, with tumor control rates between $82 \%$ and $98 \% .14,19,23,26,34,42,47$ SRS for posterior fossa meningiomas was also reported, with tumor control rates of $87 \%$ $100 \% .32,37,40$ There have only been a few reports specifically on SRS for CPA meningiomas, with tumor control rates between $92 \%$ and $100 \% .14,23,34,35$ The current study tumor control rate for CPA meningiomas was $98 \%$.

Excellent tumor control rates have also been reported with SRS for sporadic VSs, ranging between $87 \%$ and $100 \% .{ }^{8,11,18,29,38}$ Our results for sporadic VSs in the current series were comparable at a $94 \%$ tumor control rate.

\section{Surgery and Hearing}

The hearing preservation rate after surgery for CPA meningiomas is reported to be $60 \%-100 \% .^{1,2,12,46}$ Some
TABLE 5. Significant covariates in preserved hearing function (serviceable/nonserviceable) tested for the entire cohort

\begin{tabular}{|c|c|c|c|c|}
\hline \multirow[b]{2}{*}{ Covariate } & \multirow{2}{*}{$\begin{array}{l}\text { Univariate } \\
\text { Analysis } \\
\text { ( } p \text { value) }\end{array}$} & \multicolumn{3}{|c|}{ Multivariate Analysis } \\
\hline & & OR & $95 \% \mathrm{Cl}$ & $\begin{array}{c}\mathrm{p} \\
\text { Value }\end{array}$ \\
\hline $\begin{array}{l}\text { Tumor type (CPA menin- } \\
\text { gioma) }\end{array}$ & $<0.0001$ & 20.37 & $2.29-181.52$ & 0.007 \\
\hline $\begin{array}{l}\text { Pretreatment hearing } \\
\text { grade (Grade I) }\end{array}$ & $<0.0001$ & NS & NS & NS \\
\hline $\begin{array}{l}\text { CPA tumor diameter } \\
\text { (smaller) }\end{array}$ & 0.002 & NS & NS & NS \\
\hline $\begin{array}{l}\text { Length of IC tumor } \\
\text { (shorter) }\end{array}$ & $<0.0001$ & NS & NS & NS \\
\hline $\begin{array}{l}\text { Distance from lat tumor to } \\
\text { cochlea (mm) }\end{array}$ & $<0.0001$ & NS & NS & NS \\
\hline Max cochlear dose (lower) & $<0.0001$ & NS & NS & NS \\
\hline $\begin{array}{l}\text { Mean cochlear dose } \\
\text { (lower) }\end{array}$ & 0.02 & NS & NS & NS \\
\hline $\begin{array}{l}\text { Follow-up duration } \\
\text { (shorter) }\end{array}$ & $<0.0001$ & 0.98 & $0.97-0.099$ & 0.002 \\
\hline Max cochlear dose (Gy) & & NS & NS & NS \\
\hline$\leq 7$ & $<0.0001$ & & & \\
\hline \multicolumn{5}{|l|}{$>7$} \\
\hline Mean cochlear dose (Gy) & & NS & NS & NS \\
\hline$\leq 4$ & 0.01 & & & \\
\hline \multicolumn{5}{|l|}{$>4$} \\
\hline Max tumor diameter $(\mathrm{cm})$ & & NS & NS & NS \\
\hline$\leq 3$ & 0.002 & & & \\
\hline \multicolumn{5}{|l|}{$>3$} \\
\hline Tumor control & 0.004 & 10.88 & $1.96-60.31$ & 0.006 \\
\hline
\end{tabular}

Boldface type indicates statistical significance.

studies reported on the hearing preservation rate after surgery for meningiomas extending into the IAC, which was not as good, ranging from $15 \%$ to $71 \%$. $4,7,15,24,27,28,31,35$, ${ }_{41,48}$ The location of the meningiomas within the CPA was found to influence hearing outcome. Meningiomas located superior to the IAC or between the IAC and the sigmoid sinus had better hearing outcome. ${ }^{12}$ More favorable hearing outcome was also found in retromeatal compared to premeatal CPA meningiomas at increased risk of surgical damage to the neurovascular bundle in anteriorly located tumors, because of the obstacle it presents during tumor removal. ${ }^{39}$ It was also reported that the risk of hearing loss was substantially greater with VS than with CPA meningioma surgery. ${ }^{1}$ This is probably attributable to the fact that there is a more intimate relationship between VSs and the vestibulocochlear complex, which usually invade the IAC and cause significant nerve compression. ${ }^{3,6}$ Also, surgically VSs tend to be more intimately involved with the vestibulocochlear complex as they originate along the axon of the nerve, whereas meningiomas do not arise from the nerve and therefore can be more easily peeled away with less risk of nerve injury. ${ }^{1}$ Hearing preservation after GKRS in the current study compares favorably in both tumor types compared to surgery. 
TABLE 6. Significant covariates in better hearing outcome (stable/worse) tested for each tumor type separately

\begin{tabular}{|c|c|c|c|c|c|c|}
\hline \multirow[b]{3}{*}{ Covariate } & \multicolumn{2}{|c|}{ CPA Meningioma (Group A) } & \multicolumn{4}{|c|}{ VS (Group B) } \\
\hline & \multirow{2}{*}{$\begin{array}{c}\text { Univariate Analysis } \\
(p \text { value })\end{array}$} & \multirow{2}{*}{$\begin{array}{l}\text { Multivariate Analysis } \\
\text { ( } p \text { value) }\end{array}$} & \multirow{2}{*}{$\begin{array}{c}\text { Univariate Analysis } \\
\text { ( } p \text { value })\end{array}$} & \multicolumn{3}{|c|}{ Multivariate Analysis } \\
\hline & & & & OR & $95 \% \mathrm{Cl}$ & $\mathrm{p}$ Value \\
\hline Follow-up (shorter) & NS & NS & 0.003 & 0.99 & $0.98-0.099$ & 0.03 \\
\hline Max tumor diameter & NS & NS & 0.01 & NS & NS & NS \\
\hline \multicolumn{7}{|l|}{$\leq 3 \mathrm{~cm}$} \\
\hline \multicolumn{7}{|l|}{$>3 \mathrm{~cm}$} \\
\hline Tumor control & NS & NS & 0.02 & NS & NS & NS \\
\hline
\end{tabular}

Boldface type indicates statistical significance.

\section{Radiotherapy and Hearing}

CPA meningiomas have rarely been mentioned specifically in series reporting on different forms of radiotherapy for meningiomas. This is due to the rare occurrence of these tumors. Moreover, auditory function is also not commonly reported on in radiotherapy series, with more focus on tumor control and adverse radiation effects. Di Franco et al. ${ }^{13}$ reported on the use of the Cyberknife for the treatment of meningiomas with a mix of SRS and fractionated stereotactic radiotherapy (FSRT) cases. A single fraction was used to treat lesions less than $2 \mathrm{~cm}$, while FSRT was used to treat lesions greater than $2 \mathrm{~cm}$ or less than $3 \mathrm{~cm}$, but too close to a critical site, such as the optical chiasm

TABLE 7. Significant covariates in preserved hearing function (serviceable/nonserviceable) tested for each tumor type separately

\begin{tabular}{|c|c|c|c|c|}
\hline & \multicolumn{4}{|c|}{ VS (Group B) } \\
\hline & \multirow{2}{*}{$\begin{array}{c}\text { Univariate } \\
\text { Analysis } \\
\text { (p value) }\end{array}$} & \multicolumn{3}{|c|}{ Multivariate Analysis } \\
\hline & & OR & $95 \% \mathrm{Cl}$ & $\begin{array}{c}\mathrm{p} \\
\text { Value }\end{array}$ \\
\hline $\begin{array}{l}\text { CPA tumor diameter } \\
\quad \text { (smaller) }\end{array}$ & 0.001 & NS & NS & NS \\
\hline Length of IC tumor (lesser) & 0.03 & NS & NS & NS \\
\hline Max cochlear dose (lower) & 0.03 & NS & NS & NS \\
\hline Mean cochlear dose (lower) & 0.02 & NS & NS & NS \\
\hline Follow-up (shorter) & 0.001 & 0.98 & $0.97-0.99$ & 0.003 \\
\hline $\begin{array}{l}\text { Pretreatment hearing grade } \\
\text { (Grade I) }\end{array}$ & 0.009 & NS & NS & NS \\
\hline Max cochlear dose & 0.003 & 3.81 & $1.01-14.53$ & 0.04 \\
\hline \multicolumn{5}{|l|}{$\leq 7 \mathrm{~Gy}$} \\
\hline \multicolumn{5}{|l|}{$>7 \mathrm{~Gy}$} \\
\hline Mean cochlear dose & 0.03 & NS & NS & NS \\
\hline \multicolumn{5}{|l|}{$\leq 4 \mathrm{~Gy}$} \\
\hline \multicolumn{5}{|l|}{$>4 \mathrm{~Gy}$} \\
\hline Max tumor diameter & 0.01 & NS & NS & NS \\
\hline \multicolumn{5}{|l|}{$\leq 3 \mathrm{~cm}$} \\
\hline \multicolumn{5}{|l|}{$>3 \mathrm{~cm}$} \\
\hline Tumor control & 0.008 & 12.61 & $1.98-80.21$ & 0.007 \\
\hline
\end{tabular}

CPA meningiomas were excluded from the test because it was invalid as there was only 1 case that had nonserviceable hearing after treatment. Boldface type indicates statistical significance. or CPA. The study included 7 patients with CPA meningiomas. There were 6 patients with pretreatment hearing disorders. After treatment, hearing remained unchanged or improved in 5 and worsened in 1 patient. There was a new hearing deficit in 3 patients but in an unspecified location. Minniti et al..$^{30}$ treated 52 patients with large skull base meningiomas using FSRT, 5 of which were located in the CPA. Four patients initially had a hearing deficit before treatment. Progressive hearing loss was reported in 2 cases after treatment. The hearing preservation rates in the current study are the same if not better than the results reported in the previous two studies.

\section{Radiosurgery for CPA Meningiomas and Hearing}

The incidence of CPA meningiomas with serviceable hearing on presentation is reported to be $39 \%-88 \% .{ }^{23,34}$, ${ }_{35,46}$ In the current study the incidence was $27 \%$. The wide incidence variability is probably related to the location criteria, as the CPA location is a wide space located between the lateral cerebellum and pons. It extends anteriorly from the clivus to the posterior edge of the cerebellum posteriorly and from the trigeminal nerve above the jugular foramen below. In this study we applied stringent location criteria in order to include meningiomas, which mimicked VSs in location and morphology. The aim was to compare the hearing outcome in both and to determine if predictive factors of hearing outcome applied to both tumor types equally. This may explain the lower number of CPA meningiomas with serviceable hearing at presentation in the current study.

The hearing preservation rate reported in previous studies of SRS for CPA meningiomas or meningiomas around the IAC was 79\%-98\% $\%^{14,23,34,35}$ (Table 8). Regarding the predictors of hearing preservation, none of the studies that specifically analyzed the correlation with cochlear dose found any significant relationship. ${ }^{23,34}$ Similarly, the current study did not find such correlation; in fact, the cochlear doses in patients with unchanged and worse hearing were not much different. Park et al. ${ }^{34}$ suggested that the greater distance between the lateral tumor margin and the cochlea may explain the high rate of hearing preservation. We did find a relationship between IC tumor extension and hearing outcome. This may be the result of the shorter length of the nerve exposed to radiation rather than the dose to the cochlea. Pretreatment hearing status was found to have an effect on auditory function after treatment. ${ }^{14,34}$ The current study, which unlike previous studies included 
TABLE 8. Comparison of studies involving treatment of CPA meningiomas and meningiomas in and around the IAC

\begin{tabular}{|c|c|c|c|c|c|c|c|c|}
\hline Authors \& Year & $\begin{array}{l}\text { No. of Patients } \\
\text { w/ Serviceable } \\
\text { Hearing }\end{array}$ & $\begin{array}{c}\text { Prescription } \\
\text { Dose (Gy) }\end{array}$ & $\begin{array}{c}\text { Tumor } \\
\text { Volume }\left(\mathrm{cm}^{3}\right)\end{array}$ & $\begin{array}{c}\text { IC Tumor } \\
\text { Extension }(\mathrm{mm})\end{array}$ & $\begin{array}{c}\text { Max Cochlear } \\
\text { Dose (Gy) }\end{array}$ & $\begin{array}{c}\text { Follow-Up } \\
\text { Duration (Mos) }\end{array}$ & $\begin{array}{c}\text { Tumor } \\
\text { Control (\%) }\end{array}$ & $\begin{array}{c}\text { Hearing } \\
\text { Preservation } \\
\text { Rate (\%) }\end{array}$ \\
\hline Pollock et al., 2004 & 14 & Median 15 & Median 5.1 & Median 7 & NA & Median 36 & 100 & 79 \\
\hline Kim et al., 2012 & 31 & Mean 13.1 & Mean 6.1 & Mean 6.9 & Mean 6.3 & Mean 46 & 94 & 98 \\
\hline Park et al., 2014 & 29 & Median 13 & Median 3 & NA & $3.2 / 2.5 / 5.2^{*}$ & Median 40 & 97 & 97 \\
\hline Ding et al., 2014 & NA & Median 13 & Median 3.6 & NA & NA & Mean 46 & 92 & $97 \dagger$ \\
\hline Current study & 66 & Mean 11.7 & Mean 10 & Mean 4.1 & Mean 6.2 & Mean 42 & 97 & 98 \\
\hline
\end{tabular}

* Median cochlear dose in unchanged hearing, improved hearing, and worse hearing was 3.2, 2.5, and $5.2 \mathrm{~Gy}$, respectively.

$\dagger$ Calculated from total number of patients, including those with and without serviceable hearing.

only patients with serviceable hearing, found that pretreatment Grade I hearing was a positive predictor of hearing function after treatment.

\section{Radiosurgery for VS and Hearing}

The hearing preservation rate after SRS for VSs has been reported to be 50\%-78\%. 10,17,18,25,26,33,37,43 Several factors have been suggested to affect hearing preservation, including tumor volume, pretreatment hearing status, age, cochlear dose, brainstem cochlear nucleus dose, and marginal dose $\leq 13$ Gy. ${ }^{8,9,11,21,26,33,38,43,46}$ Similarly, we found that patients with Grade I hearing fared better regarding hearing preservation. This was clearly evident when we compared these patients with those with Grade II hearing. Although tumor volume was not significantly related to hearing preservation, by univariate analysis we found that CPA tumor diameter and IC tumor length significantly correlated with hearing outcome and function. We believe that they relate partly to the length of cochlear nerve exposed to radiation. The significant correlation found between the length of IC tumor extension and pretreatment hearing grade suggests that it is possible that the length of the nerve in the IAC, and consequently the degree of primary nerve affection by tumor, may also contribute to the final hearing outcome and function.

Several studies advocated that the mean cochlear dose was a major determinant in hearing preservation. ${ }^{20,22,29}$ Some have gone as far as indicating a cutoff value for the mean cochlear dose of 4 Gy. ${ }^{25,43,46}$ Others have reported on the maximum cochlear dose as a significant prognostic factor for hearing preservation. ${ }^{44}$ Kano et al..$^{22}$ indicated that a 4.2-Gy central cochlear dose was the critical cutoff value for hearing preservation. In the current study, a low marginal dose (mean $12 \mathrm{~Gy}$ ) was used that would minimize complications without compromising tumor control. Also, we were able to establish a cutoff value for the maximum cochlear dose of 7 Gy or less for hearing preservation, and although mean cochlear dose was a significant factor for hearing preservation in univariate analysis, we could not find that correlation in multivariate analysis or establish a significant relationship with the 4-Gy cutoff value. Followup duration was a significant factor common among all forms of analysis we performed, which would be expected, as with longer follow-up duration more patients who are predisposed by other factors to develop hearing loss will eventually lose hearing. It was observed that there is an accelerated rate of hearing decline in the first 2-3 years followed by slower hearing deterioration. ${ }^{8,25}$ Also, it has been suggested that hearing deterioration in longer followup may be age-related rather than treatment-related..$^{10}$

\section{Comparison Between Hearing Results for CPA Meningiomas and VSs}

There are several proposed theories to explain hearing deterioration after SRS. They include damage to the cochlear sensory cells, injury to the cochlear nerve by the tumor compression, injury to the cochlear nerve by radiation exposure, injury to the cochlear nucleus in the brainstem by radiation exposure, and compression or thrombosis of the internal auditory artery, leading to ischemic injury of the cochlea. ${ }^{12,22,33}$ These theories, however, were based on studies of SRS for VSs. The current study was aimed at investigating the applicability of these theories to CPA meningiomas.

The CPA meningioma tumor type was a major predictor of better hearing outcome and hearing function (Fig. 2). The hearing results for CPA meningiomas were much better than for VSs. The reasons for this were, firstly, a greater number of patients had Grade I hearing in meningiomas, which was significantly related to better hearing

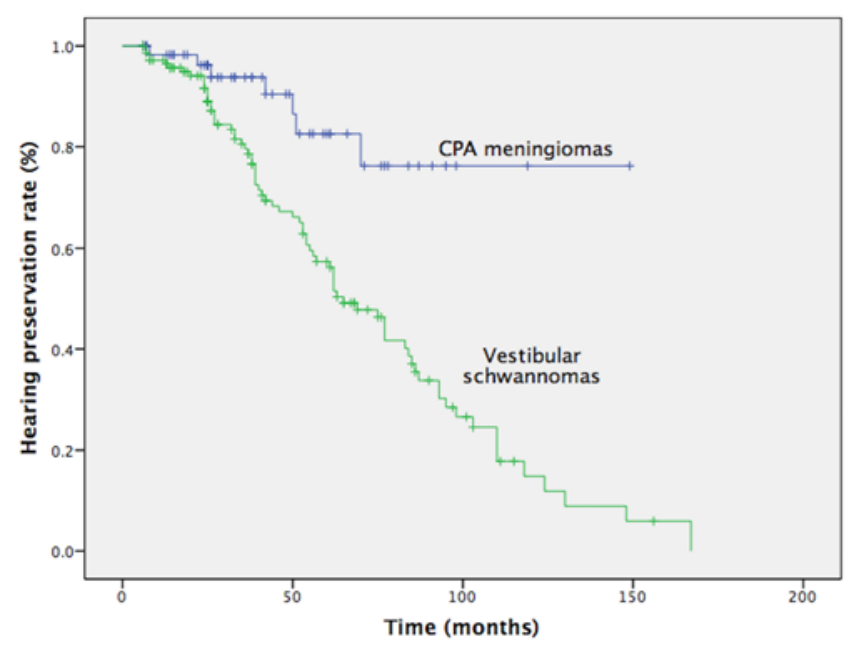

FIG. 2. Kaplan-Meier curve of hearing preservation rates for CPA meningiomas and VSs. 
function. Secondly, there was lesser IC tumor extension in meningiomas, which was also significantly related to better hearing function. Thirdly, lesser IC tumor extension would mean lower dose to the cochlea. Yet cochlear dose was not found to be significantly correlated with hearing preservation in meningiomas, so cochlear nerve radiation exposure would be a more plausible cause, especially in the narrower IAC where the cochlear nerve would be closer to the maximum target dose and hot spots inside the target. This would be especially true with VSs, which have greater IC tumor extension, so there would be greater exposure of the cochlear nerve to radiation in the narrow IAC in which the nerve is probably more compressed. It has been suggested that cochlear nerve compression by VSs may exacerbate hearing toxicity after radiosurgery. ${ }^{22,29,43}$ Finally, the higher cochlear doses in VS radiosurgery may be associated with the greater IC tumor extension in these tumors compared to CPA meningiomas; consequently, cochlear dose association with hearing may be an incidental finding rather than a major causative factor.

\section{Study Limitations}

There were some limitations to the current study, which included the retrospective design and selection biases. In addition, the majority of tumors treated were radiologically diagnosed without histopathological confirmation. First, WHO Grade I meningiomas could not be differentiated from higher tumor grades due to the lack of histopathological specimen. Yet Ding et al. ${ }^{14}$ reported that $4 \%$ of the patients underwent further surgery after primary GKRS and all of them were histopathologically confirmed to be WHO Grade I. Secondly, there could have been some crossover between the two pathologies treated based on radiological characteristics alone. However, the difference in hearing preservation between the treated CPA meningiomas and VSs (98\% and 66\%, respectively) in the current study was so large that the probability of this occurring would be unlikely to significantly affect the results. Flickinger et al. in their study ${ }^{16}$ on GKRS for imaging-diagnosed meningiomas reported that the incidence of nonmeningioma diagnosis was $2.3 \%$.

\section{Conclusions}

GKRS for CPA meningiomas provides excellent hearing preservation in addition to high tumor control rate. Hearing outcome is better with CPA meningiomas than VSs. The cochlear dose critical threshold may be higher than previously reported. Further long-term prospective studies on determinants of hearing outcome after GKS for CPA meningiomas should be conducted.

\section{References}

1. Agarwal V, Babu R, Grier J, Adogwa O, Back A, Friedman $\mathrm{AH}$, et al: Cerebellopontine angle meningiomas: postoperative outcomes in a modern cohort. Neurosurg Focus 35(6):E10, 2013

2. Bassiouni H, Hunold A, Asgari S, Stolke D: Meningiomas of the posterior petrous bone: functional outcome after microsurgery. J Neurosurg 100:1014-1024, 2004

3. Bennett M, Haynes DS: Surgical approaches and complica- tions in the removal of vestibular schwannomas. 2007. Neurosurg Clin N Am 19:331-343, vii, 2008

4. Bohrer PS, Chole RA: Unusual lesions of the internal auditory canal. Am J Otol 17:143-149, 1996

5. Bonneville F, Sarrazin JL, Marsot-Dupuch K, Iffenecker C, Cordoliani YS, Doyon D, et al: Unusual lesions of the cerebellopontine angle: a segmental approach. Radiographics 21:419-438, 2001

6. Briggs RJ, Fabinyi G, Kaye AH: Current management of acoustic neuromas: review of surgical approaches and outcomes. J Clin Neurosci 7:521-526, 2000

7. Brookler KH, Hoffman RA, Camins M, Terzakis J: Trilobed meningioma: ampulla of posterior semicircular canal, internal auditory canal, and cerebellopontine angle. Am J Otol 1:171-173, 1980

8. Carlson ML, Jacob JT, Pollock BE, Neff BA, Tombers NM, Driscoll CL, et al: Long-term hearing outcomes following stereotactic radiosurgery for vestibular schwannoma: patterns of hearing loss and variables influencing audiometric decline. J Neurosurg 118:579-587, 2013

9. Chopra R, Kondziolka D, Niranjan A, Lunsford LD, Flickinger JC: Long-term follow-up of acoustic schwannoma radiosurgery with marginal tumor doses of 12 to 13 Gy. Int J Radiat Oncol Biol Phys 68:845-851, 2007

10. Combs SE, Welzel T, Kessel K, Habermehl D, Rieken S, Schramm O, et al: Hearing preservation after radiotherapy for vestibular schwannomas is comparable to hearing deterioration in healthy adults and is accompanied by local tumor control and a highly preserved quality of life (QOL) as patients' self-reported outcome. Radiother Oncol 106:175180,2013

11. Combs SE, Welzel T, Schulz-Ertner D, Huber PE, Debus J: Differences in clinical results after LINAC-based single-dose radiosurgery versus fractionated stereotactic radiotherapy for patients with vestibular schwannomas. Int J Radiat Oncol Biol Phys 76:193-200, 2010

12. Delbrouck C, Hassid S, Massager N, Choufani G, David $\mathrm{P}$, Devriendt D, et al: Preservation of hearing in vestibular schwannomas treated by radiosurgery using Leksell Gamma Knife: preliminary report of a prospective Belgian clinical study. Acta Otorhinolaryngol Belg 57:197-204, 2003

13. Di Franco R, Borzillo V, Ravo V, Falivene S, Romano FJ, Muto M, et al: Radiosurgery and stereotactic radiotherapy with cyberknife system for meningioma treatment. Neuroradiol J 31:18-26, 2018

14. Ding D, Starke RM, Kano H, Nakaji P, Barnett GH, Mathieu $\mathrm{D}$, et al: Gamma knife radiosurgery for cerebellopontine angle meningiomas: a multicenter study. Neurosurgery 75:398-408, 2014

15. Dinh DH, Clark SB, Whitehead M, Amedee R, Bhattacharjee MB: Intracanalicular meningioma. South Med J 93:618-621, 2000

16. Flickinger JC, Kondziolka D, Maitz AH, Lunsford LD: Gamma knife radiosurgery of imaging-diagnosed intracranial meningioma. Int J Radiat Oncol Biol Phys 56:801-806, 2003

17. Frischer JM, Gruber E, Schöffmann V, Ertl A, Höftberger R, Mallouhi A, et al: Long-term outcome after Gamma Knife radiosurgery for acoustic neuroma of all Koos grades: a single-center study. J Neurosurg [epub ahead of print March 2, 2018; DOI: 10.3171/2017.8.JNS171281]

18. Hasegawa T, Kato T, Yamamoto T, Naito T, Kato N, Torii $\mathrm{J}$, et al: Long-term hearing outcomes after gamma knife surgery in patients with vestibular schwannoma with hearing preservation: evaluation in 92 patients with serial audiograms. J Neurooncol 138:283-290, 2018

19. Hasegawa T, Kida Y, Kato T, Iizuka H, Kuramitsu S, Yamamoto T: Long-term safety and efficacy of stereotactic radiosurgery for vestibular schwannomas: evaluation of 440 pa- 
tients more than 10 years after treatment with Gamma Knife surgery. J Neurosurg 118:557-565, 2013

20. Hasegawa T, Kida Y, Kato T, Iizuka H, Yamamoto T: Factors associated with hearing preservation after Gamma Knife surgery for vestibular schwannomas in patients who retain serviceable hearing. J Neurosurg 115:1078-1086, 2011

21. Jacob JT, Carlson ML, Schiefer TK, Pollock BE, Driscoll CL, Link MJ: Significance of cochlear dose in the radiosurgical treatment of vestibular schwannoma: controversies and unanswered questions. Neurosurgery 74:466-474, 2014

22. Kano H, Kondziolka D, Khan A, Flickinger JC, Lunsford LD: Predictors of hearing preservation after stereotactic radiosurgery for acoustic neuroma. J Neurosurg 111:863-873, 2009

23. Kim YH, Kim DG, Han JH, Chung HT, Kim IK, Song SW, et al: Radiosurgery for para-IAC meningiomas: the effect of radiation dose to the cochlea on hearing outcome. Int J Radiat Oncol Biol Phys 84:675-680, 2012

24. Langman AW, Jackler RK, Althaus SR: Meningioma of the internal auditory canal. Am J Otol 11:201-204, 1990

25. Lin RH, Wang TC, Lin CD, Lin HL, Chung HK, Wang CY, et al: Predictors of hearing outcomes following low-dose stereotactic radiosurgery in patients with vestibular schwannomas: a retrospective cohort review. Clin Neurol Neurosurg 162:16-21, 2017

26. Lunsford LD, Niranjan A, Flickinger JC, Maitz A, Kondziolka D: Radiosurgery of vestibular schwannomas: summary of experience in 829 cases. J Neurosurg 102 Suppl:195-199, 2005

27. Magliulo G, Zardo F, Bertin S, D'Amico R, Savastano V: Meningiomas of the internal auditory canal: two case reports. Skull Base 12:19-26, 2002

28. Martinez Devesa PM, Wareing MJ, Moffat DA: Meningioma in the internal auditory canal. J Laryngol Otol 115:48-49, 2001

29. Massager N, Nissim O, Delbrouck C, Delpierre I, Devriendt $\mathrm{D}$, Desmedt $\mathrm{F}$, et al: Irradiation of cochlear structures during vestibular schwannoma radiosurgery and associated hearing outcome. J Neurosurg 107:733-739, 2007

30. Minniti G, Clarke E, Cavallo L, Osti MF, Esposito V, Cantore $\mathrm{G}$, et al: Fractionated stereotactic conformal radiotherapy for large benign skull base meningiomas. Radiat Oncol 6:36, 2011

31. Nakamura M, Roser F, Mirzai S, Matthies C, Vorkapic P, Samii M: Meningiomas of the internal auditory canal. Neurosurgery 55:119-128, 2004

32. Nicolato A, Foroni R, Pellegrino M, Ferraresi P, Alessandrini F, Gerosa M, et al: Gamma knife radiosurgery in meningiomas of the posterior fossa. Experience with 62 treated lesions. Minim Invasive Neurosurg 44:211-217, 2001

33. Paek SH, Chung HT, Jeong SS, Park CK, Kim CY, Kim JE, et al: Hearing preservation after gamma knife stereotactic radiosurgery of vestibular schwannoma. Cancer 104:580-590, 2005

34. Park SH, Kano H, Niranjan A, Flickinger JC, Lunsford LD: Stereotactic radiosurgery for cerebellopontine angle meningiomas. J Neurosurg 120:708-715, 2014

35. Pollock BE, Link MJ, Foote RL, Stafford SL, Brown PD, Schomberg PJ: Radiosurgery as primary management for meningiomas extending into the internal auditory canal. Stereotact Funct Neurosurg 82:98-103, 2004

36. Pollock BE, Stafford SL, Link MJ, Brown PD, Garces YI, Foote RL: Single-fraction radiosurgery of benign intracranial meningiomas. Neurosurgery 71:604-613, 2012

37. Régis J, Carron R, Park MC, Soumare O, Delsanti C, Thomassin JM, et al: Wait-and-see strategy compared with proactive Gamma Knife surgery in patients with intracanalicular vestibular schwannomas. J Neurosurg 113 Suppl:105-111, 2010

38. Roos DE, Potter AE, Zacest AC: Hearing preservation after low dose linac radiosurgery for acoustic neuroma depends on initial hearing and time. Radiother Oncol 101:420-424, 2011

39. Schaller B, Merlo A, Gratzl O, Probst R: Premeatal and retromeatal cerebellopontine angle meningioma. Two distinct clinical entities. Acta Neurochir (Wien) 141:465-471, 1999

40. Sheehan JP, Starke RM, Kano H, Barnett GH, Mathieu D, Chiang V, et al: Gamma Knife radiosurgery for posterior fossa meningiomas: a multicenter study. J Neurosurg 122:1479-1489, 2015

41. Singh KP, Smyth GD, Allen IV: Intracanalicular meningioma. J Laryngol Otol 89:549-552, 1975

42. Starke RM, Williams BJ, Hiles C, Nguyen JH, Elsharkawy MY, Sheehan JP: Gamma knife surgery for skull base meningiomas. J Neurosurg 116:588-597, 2012

43. Tamura M, Carron R, Yomo S, Arkha Y, Muraciolle X, Porcheron D, et al: Hearing preservation after gamma knife radiosurgery for vestibular schwannomas presenting with high-level hearing. Neurosurgery 64:289-296, 2009

44. Timmer FC, Hanssens PE, van Haren AE, Mulder JJ, Cremers $\mathrm{CW}$, Beynon AJ, et al: Gamma knife radiosurgery for vestibular schwannomas: results of hearing preservation in relation to the cochlear radiation dose. Laryngoscope 119:1076-1081, 2009

45. Tomogane $\mathrm{Y}$, Mori K, Izumoto S, Kaba K, Ishikura R, Ando $\mathrm{K}$, et al: Usefulness of PRESTO magnetic resonance imaging for the differentiation of schwannoma and meningioma in the cerebellopontine angle. Neurol Med Chir (Tokyo) 53:482-489, 2013

46. Watanabe S, Yamamoto M, Kawabe T, Koiso T, Yamamoto T, Matsumura A, et al: Stereotactic radiosurgery for vestibular schwannomas: average 10-year follow-up results focusing on long-term hearing preservation. J Neurosurg 125 (Suppl 1):64-72, 2016

47. Zachenhofer I, Wolfsberger S, Aichholzer M, Bertalanffy A, Roessler K, Kitz K, et al: Gamma-knife radiosurgery for cranial base meningiomas: experience of tumor control, clinical course, and morbidity in a follow-up of more than 8 years. Neurosurgery 58:28-36, 2006

48. Zeitouni AG, Zagzag D, Cohen NL: Meningioma of the internal auditory canal. Ann Otol Rhinol Laryngol 106:657661,1997

\section{Disclosures}

The authors report no conflict of interest concerning the materials or methods used in this study or the findings specified in this paper.

\section{Author Contributions}

Conception and design: El-Shehaby. Acquisition of data: El-Shehaby, Abdel Karim, Nabeel, Emad Eldin, Tawadros. Analysis and interpretation of data: El-Shehaby, Abdel Karim, Nabeel. Drafting the article: El-Shehaby. Critically revising the article: Reda, Abdel Karim. Reviewed submitted version of manuscript: Reda, Abdel Karim, Nabeel, Emad Eldin, Tawadros. Statistical analysis: ElShehaby. Study supervision: El-Shehaby, Reda.

\section{Supplemental Information}

\section{Previous Presentations}

Portions of this work were presented in abstract form and as an oral presentation at the 19th International Leksell Gamma Knife Society Meeting, which was held in Dubai, United Arab Emirates, on May 4-8, 2018.

\section{Correspondence}

Amr El-Shehaby: Kornich El Nil, Nasser Institute Hospital, Gamma Knife Center Cairo, Egypt. amrelshehaby@yahoo.com. 